NACIONALES 2018

$5^{\circ}$ Congreso Argentino de Ortopedia y Traumatología

Del 1 al 4 de diciembre

Centro de Convenciones Metropolitano, Rosario, Santa Fe Página web: http://www.congresoaaot.org.ar/

Informes: congreso@ aaot.org.ar

\section{INTERNACIONALES 2018}

93 Congrès de la Société Française de Chirurgie Orthopédique et Traumatologique

Del 12 al 15 de noviembre

Francia

Página web: http://www.sofcot.fr/

Informes: Caroline.metais@eventime-group.com

\section{NACIONALES 2019}

\section{Congreso SAMECIPP}

Del 28 al 30 de marzo

Hotel Sheraton Pilar, Buenos Aires

Página web: http://www.samecipp.org.ar/ congresoSAMECIPP.html

Informes: info@martaharriague.com.ar
XVII Congreso de la Asociación Argentina de Traumatología del Deporte

Del 11 y 12 de abril

Universidad Católica Argentina, Puerto Madero, CABA Página web: http://aatd.org.ar/

Informes: aatd@aatd.org.ar

\section{INTERNACIONALES 2019}

AAOS (American Academy of Orthopaedic Surgeons) Annual Meeting 2019

Del 12 al 16 de marzo

Venetian/ Sands Expo, Las Vegas, Nevada,

Estados Unidos

Página web: https://www.aaos.org/amgeneral/

Informes: meeting@aaos.org

$14^{\circ}$ International Congress of Shoulder and Elbow Surgery (ICSES) 2019

Del 17 al 20 de septiembre

Buenos Aires

Página web: http://www.hombroycodo.org.ar

Informes: asociaciondehombroycodo@gmail.com 